\title{
Bronchoscopic Closure of Bronchopleural Fistula Using Gelfoam Versus Autologous Blood
}

\author{
FARES M. OUF, M.D.*; NABIL F. AWAD, M.D.*; KHALED M.I. HALIMA, M.D.** and \\ EMAD H.G.A. TAYEL, M.Sc.* \\ The Department of Chest Diseases, Faculty of Medicine, Al-Azhar University, Egypt
}

\begin{abstract}
Background: Diagnosis and management of bronchopleural fistula remains a major therapeutic challenge for physicians, since it is medical diagnosis and localization may be troublesome and needs various imaging techniques, likewise it is associated with a significant morbidity and fatality so fruitful bronchoscopic management is considered a perfect choice as it is less invasive procedure especially in patients who are unsuitable for surgery and standard anesthesia or associated with comorbidities, additionally it would lessen cost and lifelong hospital stay.
\end{abstract}

Aim of the Study: To compare efficacy of gelfoam and autologous blood injection in bronchoscopic closure of bronchopleural fistula.

Subjects and Methods: This study carried out at Fibrooptic Bronchoscopy Unit in Chest Department, Al-Hussein Hospital, Al-Azhar University in the period between October 2015 to October 2017. One setting of fibrooptic bronchoscopic closure trial was performed in forty patients with bronchopleural fistula using gelfoam injection in twenty patients (Group A) and autologous blood in another twenty patients (Group B) after full clinical and investigational assessment.

Results: Successful closure occurred in 19 patients $(95 \%)$ in (group A) using gelfoam and in 18 patients $(90 \%)$ in (group B) using autologous blood, the mean hospitalization time was 7.05 days in (group A) and 9.35 days in (group B) the mean time from procedure to chest tube removal was 3.2 days in (group A) and 5.75 days in (group B) also the mean time from procedure to discharge was 3.8 days in (group A) and 6.5 days in (group B) pneumothorax and death did not occur in both groups but hemoptysis occurred in 5 patients $(25 \%)$ in (group A), and 7 patients (35\%) in (group B) also cough occurred in 16 patients $(80 \%)$ in (group A), and 18 patients $(90 \%)$ in (group B) and low grade fever occurred in 12 patients $(60 \%)$ in (group A) and 15 patients $(75 \%)$ in (group B).

Conclusion: Bronchoscopic closure of bronchopleural fistula utilizing gelfoam or autologous blood is a straightfor-

Correspondence to: Dr. Khaled M.I. Halima, The Department of Chest Diseases, Faculty of Medicine, Al-Azhar University, Egypt ward procedure which can be performed safely and securely under local anesthesia with promising outcomes, it is ought to be viewed an as an ideal choice particularly in small sized fistulae in patients who are unfit for surgery and general anesthesia.

Key Words: Gelfoam versus autologous blood - Bronchopleural fistula-Bronchoscopic closure.

\section{Introduction}

BRONCHOPLEURAL fistula (BPF) is defind as an abnormal communication between tracheobronchial tree and the pleural space that may derive from a necrotizing pneumonia, empyema (tuberculous, pyogenic, anaerobic and fungal), blunt and penetrating chest injuries, lung neoplasms, or may take place as a complexity of procedures such as chest tube drainage, lung biopsy, thoracocentesis or may complicate radiation therapy, nevertheless it is ordinarily emerges as a complication of lung surgery pursuing failure of the bronchial stump to heal [1]. Effective management of BPF is joined with treatment of the associated empyema cavity therefore the first step should be control of active infection and satisfactory drainage of the hemithorax, when this occurred definitive treatment ought to be considered [2]. Bronchoscopic management idea is established on the conveyance of different materials and small devices into the BPF sites, examples include using gelfoam, autologous blood, antibiotics, ethanol injections, different glues, silicone fillers, coils, air way stents, amplatzer devices, endobronchial valves with variable achievement rates [3]. These kinds of synthetic and biologically derived substances initial plug that occludes the leak subsequently induces an inflammatory response and mucosal proliferation resulting in long term closure of BPF [4]. The properties wanted of a perfect endobronchial plug for the 
management of BPF would incorporate that it be minimally tissue reactive, easy to sterilize, radioopaque, precisely implantable by minimally invasive techniques, easily-removed and easy to be monitored in follow-up, the technique for occlusion of peripheral BPFs using gel foam as a short-term endobronchial blocker has been described by Jones et al., with the advantage that it is easily available, inserted via flexible bronchoscopy under local anesthesia, nontoxic and completely phagocytosed within one month [5]. Autologous blood injection is a safe, easy, well tolerated, inexpensive, and effective method, also no specific clinical symptoms resulting from the procedure were observed [6] Bronchoscopic management of BPF utilizing gelfoam or autologous blood seems to be an efficient and proven substitute for surgical options and being progressively utilized as therapeutic modality in the management of BPF, the procedure is easy to learn and is performed on an outpatient basis with insignificant cost and discomfort to the patient and reduced rate of trauma, also it can be performed in both stable and critically ill patients so it is a reasonable first choice in management of small BPF [7].

\section{Aim of the work:}

To compare the efficacy of gelfoam and autologous blood injection in bronchoscopic closure of bronchopleural fistula.

\section{Subjects and Methods}

This study was conducted at Endoscopy Unit in Chest Department, Al-Hussein Hospital, AlAzhar University in the period between October 2015 to October 2017. One setting of fibrooptic bronchoscopic closure trial was performed in forty patients with bronchopleural fistula using gelfoam injection in twenty patients (Group A) and autologous blood in another twenty patients (Group B) after full clinical and investigational assessment.

All patients after giving written consent were subjected to the following:

- Full history taking and clinical examination.

- Routine lab assessment, especially the bleeding profile due to the procedure, also serum albumin level as it affects the healing process of bronchopleural fistula.

- Arterial blood gases to exclude the hypoxia, and proper assessment before the procedure especially with chronic chest conditions.

- Pre procedure radiological assessment by plain chest X-ray for diagnosis of BPF, and CT chest for confirmation of diagnosis, proper segmental localization of BPF and exclusion of another associations that may postpone or abolish the procedure as large emphysematous bulla, or pneumomediastinum.

- Clamping of intercostal tube for three hours post procedure followed by radiological assessment by chest X-ray of the air leak and if not present chest tube should be removed.

- Post procedure twenty four hours, one month and six months radiological assessment by plain chest $\mathrm{X}$-ray for follow-up, evaluation of procedure complications and confirmation of complete fistula closure.

- Post procedure one and six months radiological assessment by CT chest for follow-up and confirmation of complete fistula closure.

\section{Inclusion criteria:}

Clinical and radiological diagnosis of bronchopleural fistula, persistent air leak in intercostal tube with under water seal more than two weeks in spite of proper drainage and medical therapy, confirmation of diagnosis by methylene blue injection using fibrooptic bronchoscope, and absence of contraindications for fibrooptic bronchoscopy as life threatening arrhythmia, severe hypoxemia, or bleeding tendency.

\section{Exclusion criteria:}

Associated comorbidities as recent myocardial infarction, medical conditions associated with high risk bronchoscopy as life threatening arrhythmia, severe hypoxemia, bleeding tendency that can't be corrected and severe airway obstruction (FEV 1 $<30 \%$ predicted), because all are contraindications for fibrooptic bronchoscope setting.

\section{Diagnosis of bronchopleural fistula:}

Clinical diagnosis: The acute presentation is characterized by dyspnea, cough with expectoration of purulent material or fluid, hypotension and subcutaneous emphysema, subacute presentation is more insidious and is characterized by wasting,malaise, fever, and minimally productive cough, and chronic form (which is usually associated with an infectious process) also characterized by wasting, malaise, fever and cough.

\section{Radiological diagnosis:}

Chest $X$-ray: Radiological features that are suggestive of the presence or the development of a BPF include: Steady increase in intrapleural air space, appearance of a new air fluid level, changes 
in an already present air fluid level, development of tension pneumothorax or a drop in the air fluid level exceeding $2 \mathrm{~cm}$ (if patient has no chest tube in place).

CT Chest: In computed tomography, apart from demonstration of a pneumothorax, pneumomediastinum and underlying lung pathology, the actual fistulous communication appears.

Bronchoscopic diagnosis: Fibrooptic bronchoscopy, the procedure was done under local anesthesia (lidocaine spray $10 \%$ and lidocaine hydrochloride sterile solution $2 \%, 50 \mathrm{ml}$ each $\mathrm{ml}$ contain $20 \mathrm{mg}$ ), light sedative (midazolam $15 \mathrm{mg} / 3 \mathrm{ml}$ ) after premedication with atropine, and supplemental oxygen using nasal prong during the procedure.

Fibrooptic bronchoscope (storz) was introduced through nostril or the mouth according to the presence of nasal problems or not, then diagnosis and localization of the BPF determined either by wedging the bronchoscope in each segment and simultaneously observing whether the air bubbles cease or decrease.

A small diameter catheter (OLYMPUS PR-2B) (100cm long, $1.8 \mathrm{~mm}$ diameter) passed via the operating channel of the bronchoscope and inject methylene blue $(10 \mathrm{ml}+40 \mathrm{ml}$ Normal saline $0.9 \%)$ through it then observe appearance of the blue colour in the container of chest tube that indicate the affected segment.

Bronchoscopic closure using Gelfoam, autologous blood procedure:

After diagnosis and proper localization of BPF using fibrooptic bronchoscope the catheter tip appeared about $2-3 \mathrm{~cm}$ beyond the tip of bronchoscope and the determinant amount of Gelfoam or autologous blood were injected according to each group as follow:

- In Group A: The gel piece (Cutanplast® Standard $70 \times 50 \times 10 \mathrm{~mm}$ ) which is a water insoluble material that was cut into tiny pieces and $10 \mathrm{ml}$ of normal saline could be added to the pieces to form the gelfoam that injected through the catheter which tip was placed in the segment that was earlier localized.

- In Group B: The determinant amount of autologous blood $(10 \mathrm{ml})$ and $5 \mathrm{ml}$ tranexamic acid (cyclokapron $₫ 100 \mathrm{mg} / \mathrm{ml}$ ) were injected through and the tip of catheter was placed in the segment that was earlier localized.

The bronchoscope was left in wedge position for 1 to 2 minutes till the coagulation process completed. (Normal clotting time 2-9 minutes was accelerated by adding the cyclokapron () , and to prevent regurgitation of the blood and foam, procedure was done as rapid as possible without inspection of the rest of the bronchial tree to avoid dyspnea and to minimize hypoxemia.

The intercostal tube was clamped for 3 hours following the procedure, if there was no air leak the clamp was released, and hence the intercostal drainage tube was removed.

Follow-up chest X-ray after one day, one month, six months of the procedure to confirm the closure and exclude the complications, and CT chest after one and six months of the procedure to confirm the closure and exclude the complications.

\section{Statistical analysis:}

Statistical analysis was carried out using the SPSS computer package version 21.0 (SPSS Inc., Chicago, IL, USA). The collected data were statistically managed as follows:

- For descriptive statistics: The mean \pm standard deviation (SD) was used for quantitative variables, the number and percentage were used for qualitative variables.

- For analytic statistics:The chi-squared test $\left(\mathrm{X}^{2}\right)$ was used to assess the differences in frequency for qualitative variables, while Fisher's exact test (FET) was applied if any expected cell values in a $2 \times 2$ table was $<5$,while in quantitative variables, the Independent Samples $t$-test was used to compare between the means of both groups, the statistical methods were verified, assuming a significant level of $p<0.05$.

\section{Results}

This table shows no significant statistical difference as regard outcomes, follow-up (1m) and (6m) among studied groups, also shows significant statistical difference as regard hospitalization time, time from procedure to chest tube removal, time from procedure to discharge. 
Table (1): Comparing patient's general characteristics among studied groups.

\begin{tabular}{|c|c|c|c|c|c|c|}
\hline \multirow[t]{2}{*}{ General characteristics } & \multicolumn{2}{|c|}{$\begin{array}{l}\text { Gel foam } \\
\text { Group (A) }\end{array}$} & \multicolumn{2}{|c|}{$\begin{array}{l}\text { Autologous blood } \\
\text { Group (B) }\end{array}$} & \multirow[t]{2}{*}{$\mathrm{X}^{2}(\mathrm{FET}) / \mathrm{t}$} & \multirow[t]{2}{*}{$p$-value } \\
\hline & $\mathrm{No}=2 \mathrm{C}$ & $\%$ & $\mathrm{No}=20$ & $\%$ & & \\
\hline \multicolumn{7}{|l|}{ Age (Years): } \\
\hline Mean \pm SD & \multicolumn{2}{|c|}{$49.95 \pm 7.19$} & \multicolumn{2}{|c|}{$49.4 \pm 7.58$} & 0.24 & 0.815 \\
\hline Min-Max & \multicolumn{2}{|c|}{$37.0-62.0$} & \multicolumn{2}{|c|}{$37.0-62.0$} & & \\
\hline \multicolumn{7}{|l|}{ Sex: } \\
\hline Male & 16 & 80.0 & 17 & 85.0 & 0.17 & 1.000 \\
\hline Female & 4 & 20.0 & 3 & 15.0 & & \\
\hline \multicolumn{7}{|l|}{ Smoking habit: } \\
\hline Yes & 11 & 55.0 & 13 & 65.0 & 0.42 & 0.748 \\
\hline No & 9 & 45.0 & 7 & 35.0 & & \\
\hline \multicolumn{7}{|l|}{ Co-morbidity: } \\
\hline Respiratory diseases & 9 & 45.0 & 6 & 30.0 & 2.10 & 0.552 \\
\hline Systemic diseases & 3 & 15.0 & 5 & 25.0 & & \\
\hline Malignant diseases & 8 & 40.0 & 8 & 40.0 & & \\
\hline No & 0 & 0.0 & 1 & 5.0 & & \\
\hline \multicolumn{7}{|l|}{ Previous surgery: } \\
\hline Yes & 8 & 40.0 & 9 & 45.0 & 0.10 & 1.000 \\
\hline No & 12 & 60.0 & 11 & 55.0 & & \\
\hline
\end{tabular}

Table (2): Comparing fistula characteristics among studied groups.

\begin{tabular}{|c|c|c|c|c|c|c|}
\hline \multirow{2}{*}{ Fistula characteristics } & \multicolumn{2}{|c|}{$\begin{array}{l}\text { Gel foam } \\
\text { Group (A) }\end{array}$} & \multicolumn{2}{|c|}{$\begin{array}{l}\text { Autologous blood } \\
\text { Group (B) }\end{array}$} & \multirow{2}{*}{$\begin{array}{c}\mathrm{X}^{2} \\
(\mathrm{FET}) / \mathrm{t}\end{array}$} & \multirow{2}{*}{$\begin{array}{c}p- \\
\text { value }\end{array}$} \\
\hline & $\mathrm{No}=20$ & $\%$ & $\mathrm{No}=20$ & $\%$ & & \\
\hline \multicolumn{7}{|l|}{ Etiology: } \\
\hline Post-operative & 7 & 35 & 8 & 40 & \multirow[t]{4}{*}{2.87} & \multirow[t]{4}{*}{0.413} \\
\hline Iatrogenic pneumothorax & 10 & 50 & 6 & 30 & & \\
\hline Spontaneous pneumothorax & 2 & 10 & 2 & 10 & & \\
\hline Post Infection & 1 & 5 & 4 & 20 & & \\
\hline \multicolumn{7}{|l|}{ Side: } \\
\hline Rt & 11 & 55.0 & 10 & 50.0 & \multirow[t]{2}{*}{0.10} & \multirow[t]{2}{*}{1.000} \\
\hline $\mathrm{Lt}$ & 9 & 45.0 & 10 & 50.0 & & \\
\hline \multicolumn{7}{|l|}{ Size on $C T$ : } \\
\hline Mean \pm SD & \multirow{2}{*}{\multicolumn{2}{|c|}{$\begin{array}{l}4.75 \pm 1.41 \\
3.0-9.0\end{array}$}} & \multirow{2}{*}{\multicolumn{2}{|c|}{$\begin{array}{l}4.95 \pm 1.61 \\
3.0-9.0\end{array}$}} & \multirow[t]{2}{*}{0.42} & \multirow[t]{2}{*}{0.678} \\
\hline Min-Max & & & & & & \\
\hline
\end{tabular}

Table (3): Comparing specific etiology of fistula among studied groups.

\begin{tabular}{lcccc}
\hline \multirow{2}{*}{ Specific Etiology } & \multicolumn{2}{c}{$\begin{array}{c}\text { Gel foam } \\
\text { Group (A) }\end{array}$} & \multicolumn{2}{c}{$\begin{array}{c}\text { Autologous blood } \\
\text { Group (B) }\end{array}$} \\
\cline { 2 - 5 } & No=20 & $\%$ & No=20 & $\%$ \\
\hline Post mechanical ventilation pneumothorax & 5 & 25.0 & 3 & 15.0 \\
Post CVC insertion pneumothorax & 2 & 10.0 & 1 & 5.0 \\
Post thoracocentesis air fluid level & 3 & 15.0 & 2 & 10.0 \\
Spontaneous pneumothorax & 2 & 10.0 & 2 & 10.0 \\
Post tuberculous empyema air fluid level & 1 & 5.0 & 3 & 15.0 \\
Post-operative (post Pneumectomy) & 2 & 10.0 & 2 & 10.0 \\
Post-operative (post Bilobectomy) & 3 & 15.0 & 3 & 15.0 \\
Post-operative (post lobectomy) & 2 & 10.0 & 3 & 15.0 \\
Post necrotizing pneumonia air fluid level & 0 & 0.0 & 1 & 5.0 \\
$X^{2}=3.23$ & \multicolumn{5}{c}{$p$-value $=0.919$} & \\
\hline
\end{tabular}


Table (4): Comparing post procedure complications among studied groups.

\begin{tabular}{|c|c|c|c|c|c|c|}
\hline \multirow{2}{*}{$\begin{array}{l}\text { Complication of } \\
\text { procedure }\end{array}$} & \multicolumn{2}{|c|}{$\begin{array}{l}\text { Gel foam } \\
\text { Group (A) }\end{array}$} & \multicolumn{2}{|c|}{$\begin{array}{l}\text { Autologous blood } \\
\text { Group (B) }\end{array}$} & \multirow{2}{*}{ FET } & \multirow{2}{*}{$p$-value } \\
\hline & $\mathrm{No}=20$ & $\%$ & $\mathrm{No}=20$ & $\%$ & & \\
\hline $\begin{array}{c}\text { Hemoptysis: } \\
\text { Yes } \\
\text { No }\end{array}$ & $\begin{array}{l}5 \\
15\end{array}$ & $\begin{array}{l}25.0 \\
75.0\end{array}$ & $\begin{array}{l}7 \\
13\end{array}$ & $\begin{array}{l}35.0 \\
65.0\end{array}$ & 0.48 & 0.731 \\
\hline $\begin{array}{c}\text { Cough: } \\
\text { Yes } \\
\text { No }\end{array}$ & $\begin{array}{l}16 \\
4\end{array}$ & $\begin{array}{l}80.0 \\
20.0\end{array}$ & $\begin{array}{l}18 \\
2\end{array}$ & $\begin{array}{l}90.0 \\
10.0\end{array}$ & 0.78 & 0.661 \\
\hline $\begin{array}{c}\text { Low Grade Fever: } \\
\text { Yes } \\
\text { No }\end{array}$ & $\begin{array}{l}12 \\
8\end{array}$ & $\begin{array}{l}60.0 \\
40.0\end{array}$ & $\begin{array}{l}15 \\
5\end{array}$ & $\begin{array}{l}75.0 \\
25.0\end{array}$ & 1.03 & 0.501 \\
\hline $\begin{array}{l}\text { Pneumothorax: } \\
\text { Yes } \\
\text { No }\end{array}$ & $\begin{array}{l}0 \\
20\end{array}$ & $\begin{array}{l}0.0 \\
100.0\end{array}$ & $\begin{array}{l}0 \\
20\end{array}$ & $\begin{array}{l}0.0 \\
100.0\end{array}$ & - & - \\
\hline $\begin{array}{l}\text { Mortality: } \\
\text { Yes } \\
\text { No }\end{array}$ & $\begin{array}{l}0 \\
20\end{array}$ & $\begin{array}{l}0.0 \\
100.0\end{array}$ & $\begin{array}{l}0 \\
20\end{array}$ & $\begin{array}{l}0.0 \\
100.0\end{array}$ & - & - \\
\hline
\end{tabular}

Table (5):Comparing procedure outcome, follow-up among studied groups.

\begin{tabular}{|c|c|c|c|c|c|c|}
\hline \multirow[t]{2}{*}{ Outcome and follow-up } & \multicolumn{2}{|c|}{$\begin{array}{l}\text { Gel foam } \\
\text { Group (A) }\end{array}$} & \multicolumn{2}{|c|}{$\begin{array}{l}\text { Autologous blood } \\
\text { Group (B) }\end{array}$} & \multirow[t]{2}{*}{$\mathrm{FET} / \mathrm{t}$} & \multirow[t]{2}{*}{$p$-value } \\
\hline & $\mathrm{No}=20$ & $\%$ & $\mathrm{No}=20$ & $\%$ & & \\
\hline $\begin{array}{l}\text { Procedure outcome: } \\
\text { Successful } \\
\text { Un successful }\end{array}$ & $\begin{array}{l}19 \\
1\end{array}$ & $\begin{array}{l}95.0 \\
5.0\end{array}$ & $2^{18}$ & $\begin{array}{l}90.0 \\
10.0\end{array}$ & 0.36 & 1.000 \\
\hline $\begin{array}{l}\text { Hospitalization time: } \\
\text { Mean } \pm \text { SD } \\
\text { Min }- \text { Max }\end{array}$ & \multicolumn{2}{|c|}{$\begin{array}{c}7.05 \pm 2.04 \\
5.0-14.0\end{array}$} & \multicolumn{2}{|c|}{$\begin{array}{c}9.35 \pm 3.56 \\
7.0-21.0\end{array}$} & 2.51 & $0.017 *$ \\
\hline $\begin{array}{l}\text { Time from procedure to } \\
\text { tube removal: } \\
\text { Mean } \pm \text { SD } \\
\text { Min-Max }\end{array}$ & \multicolumn{2}{|c|}{$\begin{array}{c}3.2 \pm 1.28 \\
2.0-6.0\end{array}$} & \multicolumn{2}{|c|}{$\begin{array}{l}5.75 \pm 2.38 \\
5.0-9.0\end{array}$} & 4.22 & $<0.001 *$ \\
\hline $\begin{array}{l}\text { Time from procedure to } \\
\text { discharge: } \\
\text { Mean } \pm \text { SD } \\
\text { Min-Max }\end{array}$ & \multicolumn{2}{|c|}{$\begin{array}{c}3.8 \pm 1.36 \\
3.0-7.0\end{array}$} & \multicolumn{2}{|c|}{$\begin{array}{c}6.5 \pm 2.48 \\
6.0-10.0\end{array}$} & 4.27 & $<0.001 *$ \\
\hline $\begin{array}{l}\text { Follow-up }(1 \mathrm{~m}): \\
\text { Alive, symptom free } \\
\text { Alive, present BPF }\end{array}$ & $\begin{array}{l}19 \\
1\end{array}$ & $\begin{array}{l}95.0 \\
5.0\end{array}$ & $2^{18}$ & $\begin{array}{l}90.0 \\
10.0\end{array}$ & 0.36 & 1.000 \\
\hline $\begin{array}{l}\text { Follow-up }(6 m) \text { : } \\
\text { Alive, symptom free } \\
\text { Died }\end{array}$ & $\begin{array}{l}19 \\
1\end{array}$ & $\begin{array}{l}95.0 \\
5.0\end{array}$ & $2^{18}$ & $\begin{array}{l}90.0 \\
10.0\end{array}$ & 0.36 & 1.000 \\
\hline
\end{tabular}

* Significant.

\section{Discussion}

This current study included forty patients with bronchopleural fistula, as regard age the group (A) contains twenty patients with age range (37-62) years, mean (49.95) and SD (7.19), on the other hand the group (B) contains twenty patients with age range (37-62) years, mean (49.4) and SD (7.58) with $p$-value (0.815) and no significant statistical difference. As regard sex the group (A) contains 16 patients $(80 \%)$ males and 4 patients $(20 \%)$ females, on the other hand the group (B) contains 17 patients $(85 \%)$ males and 3 patients $(15 \%)$ females with $p$-value (1.000) and no significant statistical difference. Jones and David in 1986 reported a case study utilizing gelfoam for A 60- 
year's old woman [5]. Seung Heon Lee and his colleagues in 2002 [8] reported a case study of 58years old man utilizing gelfoam. Also Shah AM and his colleagues in 2004 [9] reported a case study of 55 years old man utilizing gelfoam. On the other hand Ray-Shee Lan and his colleagues in 1987 [10] reported a case study of 50 years old man utilizing intrabronchial injection of patient blood. Also Gregory Wiaterek and his colleagues in 2013 [11] reported a case study of 56 years old woman utilizing intrabronchial injection of patient blood. While Bivhusal Thapa and his colleagues in 2015 [12] reported a study of 76 patients with age range (18-80) years and mean $(45.9 \pm 19.9)$ with sex ratio (M:F) 4:1, utilizing autologous blood patching through chest tube. As regard smoking habit the group (A) contains 11patients (55\%) smokers and 9 patients $(45 \%)$ nonsmokers, on the other hand the group (B) contains 13 patients $(65 \%)$ smokers and 7 patients $(35 \%)$ nonsmokers with $p$-value $(0.748)$ and no significant statistical difference in agreement with Bivhusal Thapa and his colleagues in 2015 who reported that 24 nonsmokers, 52 patients current/past smokers with range 3-50 and mean $(23.1 \pm 12.0)$ pack years with $p$-value (0.958) and no significant statistical difference. As regard general comorbidity: 9 patients $(45 \%)$ have respiratory diseases in group (A) and 6 patients (30\%) in group (B), 8 patients (40\%) have malignant diseases in group (A) and group (B), 3 patents $(15 \%)$ have systemic diseases in group $(\mathrm{A})$ and 5 patients (25\%) in group (B) and one patient (5\%) without any comorbidity in group (B), with $p$-value (1.000) and no significant statistical difference. As regard previous surgery the group (A): Contains 8 patients $(40 \%)$ with history of previous surgery and 12 patients $(60 \%)$ with no history, on the other hand the group (B) contains 9 patients (45\%) with history of previous surgery and 11 patients $(55 \%)$ with no history and $p$-value (1.000) with no significant statistical difference. Only Jones and David 1986 study includes patient with previous history of surgery as wedge resection of adenocarcinoma mass. As regard general etiology: 7 patients (35\%) have post-operative etiology in group (A) and 8 patients $(40 \%)$ in group (B), 10 patients $(50 \%)$ due to iatrogenic pneumothorax in group (A) and 6 patients (30\%) in group (B), 2 patents $(10 \%)$ due to spontaneous pneumothorax in both groups, one patient (5\%) has post infection etiology in group (A) and 4 patient (20\%) in group (B), with $p$-value (0.413) and no significant statistical difference. As regard specific etiology 5 patients $(25 \%)$ were due to post mechanical ventilation pneumothorax in group (A) and 3 patients (15\%) in group (B), 2 patients $(10 \%)$ were due to post CVC insertion pneumothorax in group (A) and one patient in group (B) 3 patients (15\%) were due to post thoracocentesis air fluid level in group (A) and 2 patients (10\%) in group (B), 2 patients $(10 \%)$ were due to persistent spontaneous pneumothorax in both groups, one patient (5\%) was due to post tuberculous empyema air fluid level in group (A) and 3 patients (15\%) in group (B), 2 patients (10\%) were due to post-operative complications (pneumectomy) in both groups, 3 patients (15\%) were due to post-operative (bilobectomy) in both groups, 2 patients (10\%) were due to post-operative (lobectomy) in group (A) and 3 patients (15\%) in group (B), also one patient $(5 \%)$ was due to post necrotizing pneumonia air fluid level in group (B) only, with $p$-value (0.919) and no significant statistical difference. Postoperative resection of Adenocarcinoma mass, thoracostomy after necrotizing pneumonia, and post streptococcal pneumonia hydro pneumothorax were the etiology $[3,9,13]$ utilizing gelfoam in their reports, on the other hand insertion of a chest tube in patient with bullous lung due to pneumoconiosis, and cavitary lung lesion due to necrotizing pneumonia were the risk factors [10,11] utilizing intrabronchial injection of patient blood in their reports. As regard side of fistula it was right sided in 11 patients $(55 \%)$ in group (A) and 10 patients (50\%) in group (B), while fistula it was left sided in 9 patients $(45 \%)$ in group (A) and 10 patients (50\%) in group (B) with $p$-value (1.000) and no significant statistical difference. It was right sided $[\mathbf{8 , 1 3}]$, while left sided [9] report utilizing gelfoam, on the other hand it was right sided [7] and left sided in [11] utilizing intrabronchial injection of patient blood. As regard size of fistula the minimal size was $3 \mathrm{~mm}$ and maximum size was $9 \mathrm{~mm}$ in both groups, with Mean $\pm \mathrm{SD}(4.75 \pm 1.41)$ in group (A) and (4.95 \pm 1.61$)$ in group (B), $p$-value (0.678) with no significant statistical difference, it was 3mm in Shah AM 2004 and $5 \mathrm{~mm}$ [11] utilizing intrabronchial injection of gelfoam and patient blood respectively. Regarding the procedure outcome it was successful in 19 patients $(95 \%)$ and unsuccessful in one patient $(5 \%)$ in group (A) while successful in 18 patients $(90 \%)$ and unsuccessful in 2 patients $(10 \%)$ in group (B) with $p$-value (1.000) and no significant statistical difference, also it was successful in one patient $[\mathbf{8 , 9 , 1 3 ]}$ utilizing gelfoam, Ray-Shee Lan et al. and Gregory et al., reports utilizing bronchoscopic autologous blood patching and in 44 patients (57.9\%) of total 76 in Bivhusal Thapa 2015 report utilizing autologous blood patching through chest tube. On the other hand $[\mathbf{8 , 9 , 1 3 ]}$. Puskas and his colleagues [13] reported that the surgical management of BPF using flab closure achieved success 
in $36(86 \%)$ of 42 patients, and in comparison to our study the difference is not considerable but as regard the risk of general anesthesia and postoperative complications the difference should be considered. There was statistical significant difference between both groups regarding mean duration of hospitalization the minimal time was 5 days in group (A) and 7 days in group (B) also maximum time was 14 days in group (A) and 21 days in group (B) with Mean \pm SD $(7.05 \pm 2.04)$ in group (A) and (9.35 \pm 3.56$)$ in group (B), and $p$-value (0.017) with significant statistical difference as it is higher in group (B) than group (A) this may be due to the time needed for proper occlusion of bronchopleural fistula by gelfoam is less than of autologous blood as gelfoam is extrinsic substance so it is reaction is rapid and occlusion process occurs earlier than autologous blood this leads to less duration of hospitalization and reduced cost of patient management. As regard mean time passed from procedure to chest tube removal among studied groups the least time was 2 days in group (A) and 5 days in group (B), on the other hand maximum time was 6 days in group (A) and 9 days in group (B) with Mean $\pm \mathrm{SD}(3.2 \pm 1.28)$ in group (A) and (5.75 \pm 2.38$)$ in group (B) with $p$-value $(<0.001)$ and significant statistical difference as it is higher in group (B) than group (A), this may be due to the time needed for chest tube removal is mainly dependent on the time needed for proper occlusion of bronchopleural fistula and complete absence of air leak, this time is less in using gelfoam than autologous blood as described before it is extrinsic substance (gelfoam) so reaction and inflammatory process resulted using it more than autologous blood this leads to earlier and superior closure of bronchopleural fistula using gelfoam that reflected on time needed for chest tube removal, in one case of group (A) and two cases of group (B) the chest tubes were not removed. Utilizing gelfoam Jones 1986 reported 5 days after the last procedure which was recurrent three times, Seung Heon et al. [8] reported 9 days, and Shah et al. [9] reported one day for chest tube removal post procedure, while Ray-Shee et al. [10] reported 10 days after the last procedure which was recurrent three times adding tetracycline at the last one and Gregory et al. [11] reported 2 days needed for chest tube removal using autologous blood injection by bronchoscope, on the other hand chest tube removal needs more time [12] by injection of blood through chest tube, and in John et al. [13] report of surgical management of BPF using flab closure. As regard mean time passed from procedure to discharge among studied groups the least time was 3 days in group (A) and 6 days in group (B) on the other hand maximum time was 7 days in group (A) and 10 days in group (B) with Mean $\pm \mathrm{SD}(3.8 \pm 1.36)$ in group (A) and (6.5 \pm 2.48$)$ in group (B) and $p$ value $(<0.001)$ with significant statistical difference as it is higher in group (B) than group (A), this due to the time needed for discharge after procedure is mainly dependent on time needed for closure of BPF and removal of chest tube that depends on substance used in closure process whenever it is more extrinsic and induce more inflammation the closure will be rapid and successful so closure using gelfoam is more rapid and discharge is earlier than using autologous blood. In one case of gelfoam group (A) and two cases of autologous blood group (B) the patients were not discharged and referred to cardiothoracic surgery, Utilizing gelfoam Jones 1986 reported 6 days after the last procedure which was recurrent three times, Seung Heon et al. [8] reported 10 days, and Shah et al. [9] reported two days for post procedure discharge, while Ray-Shee Lan et al. [10] reported 11 days after the last procedure which was recurrent three times adding tetracycline at the last one and Gregory et al. [11] reported 3 days needed for post procedure discharge using autologous blood injection by bronchoscope, on the other hand it needs more time in Bivhusal et al., report [12] by injection of blood through chest tube, and in John et al., report [13] of surgical management of BPF using flab closure, this may be due to postoperative complications by flab closure. As regard post procedure follow-up after 1 month among studied groups 19 patients (95\%) were alive and symptomatic free and one patient (5\%) was alive but still with BPF in group (A) on the other hand 18 patients were alive and symptomatic free and 2 patients (10\%) were alive but still with BPF in group (B) with $p$-value (1.000) and no significant statistical difference but this difference in follow-up results due to large size of fistula in these patients and poor general condition of them as they suffered from malignancy on chemotherapy treatment so proper closure did not occur and referred to cardiothoracic surgery department. As regard post procedure follow-up after 6 month among studied groups 19 patients (95\%) were alive and symptomatic free, one patient $(5 \%)$ died in group (A) while 18 patients were alive and symptomatic free and 2 patients (10\%) died in group (B) with $p$-value (1.000) and no significant statistical difference, but this difference in follow-up results due to poor general condition of these patients as they suffered from malignancy and chemotherapy treatment, also the cause of death not due to procedure but due to bad general conditions and underling diseases as malignancy. As regard post procedure hemoptysis it's occurred in 
5 patients $(25 \%)$ in group (A) and in 7 patients $(35 \%)$ in group (B) with $p$-value $(0.731)$ and no significant statistical difference, due to individual patients vary in their anatomy and passage of fibrooptic bronchoscope in tracheobronchial tree may causing trauma to its minute vessels leading to hemoptysis and the difference due to injection of blood in group (B). Regarding post procedure cough it's occurred in 16 patients $(80 \%)$ and did not occurred in 4 patients $(20 \%)$ in group (A)but in group (B) it's occurred in 18 patients $(90 \%)$ and did not occurred in 2 patients (10\%), with $p$-value $(0.661)$ and no significant statistical difference due to sensation of a foreign object, response to medications vary in individual patients so cough occurred commonly and there is no guarantee that a procedure can be free of complications. As regard post procedure low grade fever it's occurred in 12 patients $(60 \%)$ and did not occurred in 8 patients $(40 \%)$ in group (A), but in group (B) it's occurred in 15 patients $(75 \%)$ and did not occurred in 5 patients $(25 \%)$ with $p$-value $(0.501)$ and no significant statistical difference this may be due to systemic inflammatory response resulted from pro inflammatory cytokines release such as tumor necrosis factor and interlukin-1 in response to fibrooptic bronchoscope without any bacteremia as these substances considered a central features of systemic inflammation nowadays. Regarding post procedure pneumothorax and mortality it did not occurred in any patient in both groups, this reflects the safety of bronchoscopic closure of bronchopleural fistula. On the other hand cough and dyspnea occurred $[\mathbf{8 , 9 , 1 3 ]}$ hemoptysis and chest pain [10,11], while occurred in 7 patients (Empyema 3 , Surgical emphysema 1, pneumothorax 1, Recurrence 2) [12] with no significant statistical difference. Also another study reported by John and his colleagues [13] on surgical management of BPF using flab closure 4 deaths from 42 patients occurred as a complication of surgery during hospital stay.

\section{References}

1- MCMANIGLE J.E., FLETCHER G.L. and TENHOLDER M.F.: Bronchoscopy in the management of bronchopleural fistula. Chest, 97: 1235-1238, 1990.
2- Indian Journal of Chest Diseses Allied Scince, 52: $97-$ 104, 2010.

3- BELLATO V., FERRAROLI G.M. and DE CARIA D.: Management of postoperative bronchopleural fistula with a tracheobronchial stent in a patient requiring mechanical ventilation. Intensive Care Med., 36: 721-2, 2010.

4- TAKAOKA K., INOUE S. and OHIRA S.: Central Bronchopleural fistulas closed by bronchoscopic injection of absolute ethanol. Chest, 122: 374-8, 2002.

5- JONES D.P. and DAVID I.: Gelfoam occlusion of peripheral bronchopleural fistulas. Ann. Thorac. Surg., 42: 334$35,1986$.

6- DROGHETTI A.,SCHIAVINI A.,MURIANA P.,COMEL A., DE DONNO G., BECCARIA M., CANNETO B., STURANI C. and MURIANA G.: J. Thorac. Cardiovasc. Surg. Sep., 132 (3): 556-9, 2006.

7- LOIS M. and NOPPEN M.: Bronchopleural fistulas: An overview of the problem with special focus on endoscopic management. Chest, 128: 3955-65, 2005.

8- SEUNG HEON L., GYU Y.H., JE H.K., SANG Y.L., et al.: A Case of Peripheral Bronchopleural Fistula Treated by Flexible Bronchoscopy with Gelfoam Occlusion. Tuberc Respir Dis. Aug., 53 (2): 221-226, 2002.

9- SHAH A.M., SINGHAL P., CHHAJED P.N., ATHAVALE A., KRISHNAN R. and SHAH A.C.: Bronchoscopic closure of bronchopleural fistula using gelfoam. J. Assoc. Physicians India, 52: 508-9, 2004.

10- RAY-SHEE LAN, CHENG-HUEI LEE, YING-HUANG TSAI, WEN-LYE WANG and CHAU HSIUNG CHANG: Fiberooptic bronchial blockade in a small bronchopleural fistula. Chest. Nov., 92 (5): 944-6, 1987.

11- GREGORY W., HANS L., RAJIV M. and WES S.: Bronchoscopic Blood Patch for Treatment of Persistent Alveolar-Pleural Fistula. Journal of Bronchology and Interventional Pulmonology. April, 20 (2): 171-4, 2013.

12- BIVHUSAL T., RANJAN S. and PRAKASH S.: Autologous blood patching in the management of bronchopleural fistula in spontaneous pneumothorax, Journal of Society of Surgeons of Nepal., 18 (2): 23-28, 2015.

13- JOHN D.P., DOUGLAS J.M., HERMES C.G., et al.: Treatment strategies for bronchopleural fistula. Journal Thorac. Cardiovasc. Sueg., 109: 989-96, 1995. 


\section{أستخلدام الهنظار الشعبى فى فلق الناسور الشعبى البللورى الهوى

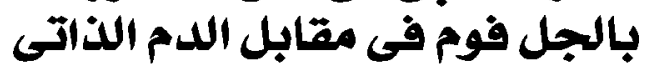

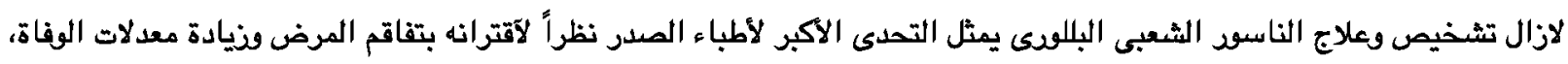

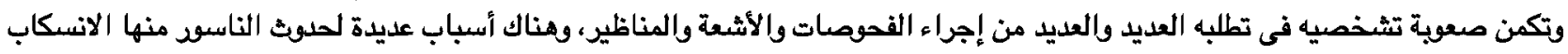

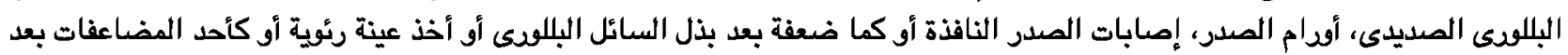

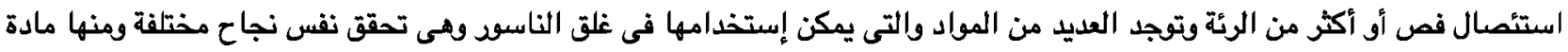

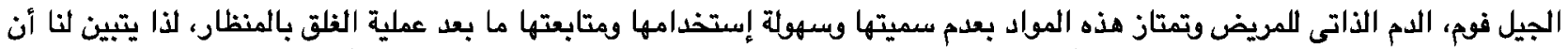

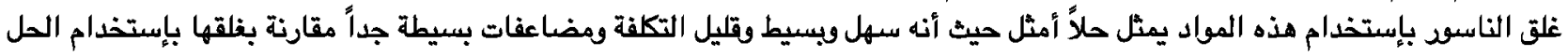

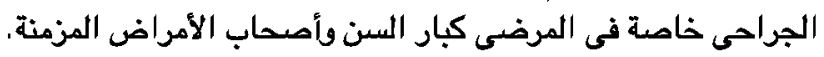

وقد صممت هذه الدراسة لمقارنة كفاءة كل من الجيل فوم والدم الذاتى في غلق الناسود الشعبى البللودى بإستخدام المنظار الشعبى

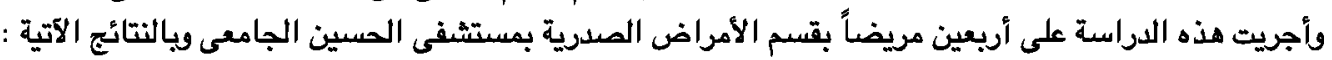

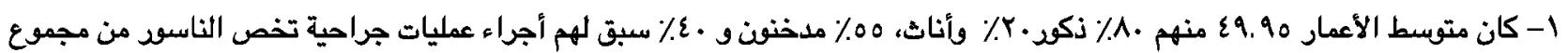

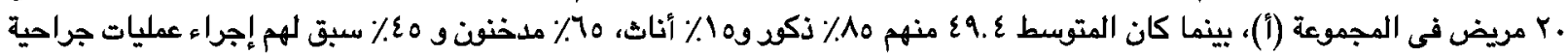

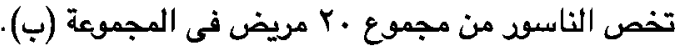

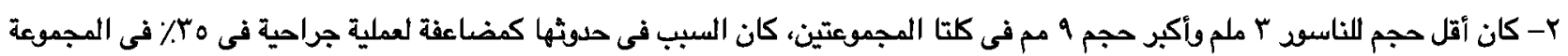

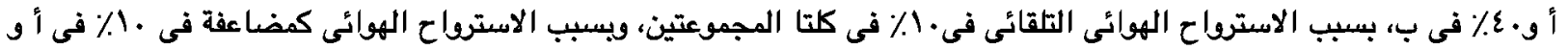

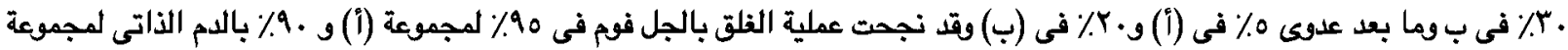

r- كان هناك تباينا ملحوظا فى كل من متوسط الوقت الكلى للحجز بالمستشفى، متوسط الوقت المستغرق لإزالة الأنبوبة الصدرية ما بعد عملية

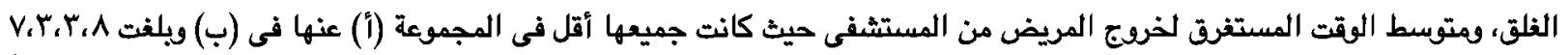

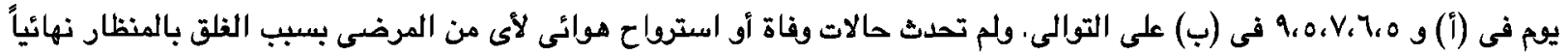
وترواحت نسب حدوث الكحة والنفث الدموى والحرارة بينهما وأكثر فى (ب).

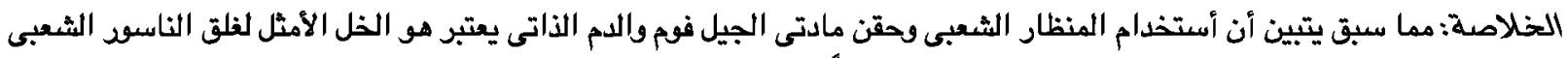

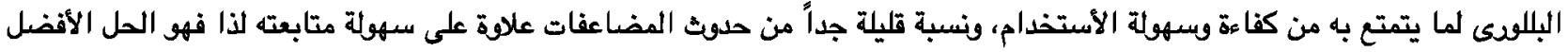

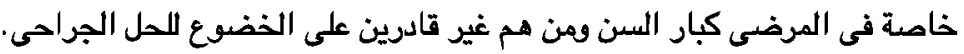

